\title{
ON ABSTRACT BARENBLATT EQUATIONS
}

\author{
CARoline BAuZET AND Guy VAllet
}

\begin{abstract}
In this paper we are interested in abstract problems of Barenblatt's type. In a first part, we investigate the problem $f\left(\partial_{t} u\right)+A u=g$ where $f$ and $A$ are maximal monotone operators and by assuming that $A$ derives from a potential $J$. With general assumptions on the operators, we prove the existence of a solution. In the second part of the paper, we examine a stochastic version of the above problem: $f\left[\partial_{t}\left(u-\int_{0}^{t} h d w\right)\right]+A u=0$, with some restrictive assumptions on the data due principally to the framework of the Itô integral.
\end{abstract}

Mathematics subject classification (2010): 47J35, 35L90.

Keywords and phrases: abstract Barenblatt equation, monotone operators, stochastic equation.

\section{REFERENCES}

[1] R. A. Adams, Sobolev spaces, Pure and Applied Mathematics, 65, A Series of Monographs and Textbooks, New York, 1975.

[2] N. S. Adimurthi And G. Vallet, On the equation of Barenblatt-Sobolev, Communications in Contemporary Mathematics, to appear.

[3] V. BARBU, Nonlinear differential equations of monotone types in Banach spaces, Springer Monographs in Mathematics, Springer, New York, 2010.

[4] G. I. Barenblatt, Similarity, self-similarity, and intermediate asymptotics, New York, London: Consultants Bureau, XVII, 1979.

[5] C. BAuZet, J. Giacomoni And G. VAllet, On a class of quasilinear Barenblatt equations, Revista Real Academia de Ciencias de Zaragoza, to appear.

[6] J. M. BORWEIN AND J. D. VANDERWERFF, Convex functions: constructions, characterizations and counterexamples, Volume 109 of Encyclopedia of Mathematics and its Applications, Cambridge University Press, Cambridge, 2010.

[7] C. Chen AND G. Cheng, Anomalous dimension in the solution of the Barenblatt's equation, J. Math. Phys., 39, 3 (1998), 1589-1600.

[8] P. Colli, On some doubly nonlinear evolution equations in Banach spaces, Japan J. Indust. Appl. Math., 9, 2 (1992), 181-203.

[9] G. DÍAZ AND J. I. DíAZ, Finite extinction time for a class of nonlinear parabolic equations, Comm. Partial Differential Equations, 4, 11 (1979), 1213-1231.

[10] J. I. DíAZ, J. S. LANGA AND J. VALERO, On the asymptotic behaviour of solutions of a stochastic energy balance climate model, Phys. D, 238, 9-10 (2009), 880-887.

[11] L. Diening, P. Harjulehto, P. Hästö And M. RuZicka, Lebesgue and Sobolev Spaces with Variable Exponents, Springer, 2011.

[12] K. S. HA, Sur des semi-groupes non linéaires dans les espaces $L^{\infty}(\Omega)$, J. Math. Soc. Japan, 31, 4 (1979), 593-622.

[13] J. Hulshof AND J.-L. VÁZQUEZ, Self-similar solutions of the second kind for the modified porous medium equation, European J. Appl. Math., 5, 3 (1994), 391-403.

[14] S. Kamin, L. A. Peletier AND J. L. VÁZquez, On the Barenblatt equation of elastoplastic filtration, Indiana Univ. Math. J., 40, 4 (1991), 1333-1362.

[15] Y. KonishI, On the nonlinear semi-groups associated with $u_{t}=\Delta \beta(u)$ and $\varphi\left(u_{t}\right)=\Delta u$, J. Math. Soc. Japan, 25, (1973), 622-628. 
[16] N. IGBIDA, Solutions auto-similaires pour une équation de Barenblatt, Rev. Mat. Apl., 17, 1 (1996), 21-36.

[17] C. PRÉVÔT C. AND M. RÖCKNER, A concise course on stochastic partial differential equations, Vol. 1905 of Lecture Notes in Mathematics, Springer, Berlin, 2007.

[18] G. Schimperna, A. Segatti And U. Stefanelli, Well-posedness and long-time behavior for a class of doubly nonlinear equations, Discrete Contin. Dyn. Syst., 18, 1 (2007), 15-38.

[19] R. E. SHOWALTER, Monotone operators in Banach space and nonlinear partial differential equations, Vol. 49 of Mathematical Surveys and Monographs, American Mathematical Society, Providence RI, 1997.

[20] G. VALlet, Stochastic perturbation of nonlinear degenerate parabolic problems, Differential and integral equation, 21, 11-12 (2008), 1055-1082.

[21] G. VAlLET AND P. WittBold, On a stochastic first-order hyperbolic equation in a bounded domain, Infinite Dimensional Analysis, QuantumProbability, 12, 4 (2009), 1-39. 